Ann Intern Med. Author manuscript; available in PMC 2013 September 09.

Published in final edited form as:

Ann Intern Med. 2012 September 18; 157(6): 456-459. doi:10.7326/0003-4819-157-6-201209180-00018.

\title{
Dialogue on Geriatrics: How Should We Fix the Problem?
}

\author{
Kenneth M. Madden, MD, MSc and \\ University of British Columbia, Vancouver, British Columbia V5Z 1M9, Canada \\ Kenneth Rockwood, MD \\ Dalhousie University, Halifax, Nova Scotia B3H 2E1, Canada
}

\section{TO THE EDITOR}

The In the Balance article by Golden and colleagues (1) has resulted in a great deal of discussion throughout geriatric medicine programs in Canada. Because geriatric medicine here is a consultative subspecialty as opposed to a primary care discipline, we believe that the situation in Canada is sufficiently different that there is no need to advocate for the "mercy-killing" of Canadian geriatrics. Canadian trainees avidly read Annals and need to be aware that even if this line of reasoning holds in the United States (about which we are dubious), it does not hold in Canada.

In our view, Golden and colleagues have made the error of confusing the Pareto principle with being an expert. The Pareto effect (2) is the well-established phenomenon where $80 \%$ of all problems can be solved with only $20 \%$ of the knowledge base. This is why a welltrained generalist is an essential part of the health care system, because he or she can efficiently and easily deal with $80 \%$ of medical issues. No one in the Canadian health care system claims that all (or even most) older adults should be treated by a geriatrician, any more than all arthritis patients should be cared for by a rheumatologist. Geriatric medicine subspecialists are best utilized by treating the minority of patients with multiple complexities due to frailty—not in internecine squabbles over all patients with graying hair.

Frailty is a highly age-associated state of increasing risk due to an accumulation of deficits that reflect multisystem physiologic changes (3). Firing a shotgun blast of subspecialists to evaluate each organ system independently is both ineffective and expensive, a circumstance remediated by the comprehensive geriatrics assessment (CGA). The most recent metaanalysis showed that the CGA (compared with usual care) reduced patient mortality, increased the chance that a patient would return home, and increased postdischarge cognitive function (4). The research on which the CGA is built requires disciplinary knowledge if it is to be advanced. By not mentioning how the complexity of frailty challenges current models of care, Golden and colleagues miss the entire point of the subspecialty.

Potential Conflicts of Interest: Dr. Rockwood: Employment: Division of Geriatrics, Faculty of Medicine, Dalhousie University; Other: member of the American Geriatrics Society, the British Geriatrics Society, and the Canadian Geriatrics Society; past-president of the Canadian Society of Geriatric Medicine; serves on the editorial board for several geriatric journals; author on Brocklehurst's Textbook of Geriatric Medicine. 
There obviously are many issues for Canadian geriatricians to grapple with, such as to what extent they should be involved at the primary care level, the balance between clinical care and research to advance the specialty, and whether more remuneration alone is a fix. We will be addressing these issues in an upcoming issue of the Canadian Geriatrics Journal (5).

\section{References}

1. Golden AG, Silverman MA, Mintzer MJ. Is geriatric medicine terminally ill? Ann Intern Med. 2012; 156:654-6. [PubMed: 22547474]

2. Pareto, V. Manual of Political Economy. New York: A.M. Kelley; 1971.

3. Rockwood K, Mitnitski A. Frailty defined by deficit accumulation and geriatric medicine defined by frailty. Clin Geriatr Med. 2011; 27:17-26. [PubMed: 21093719]

4. Ellis G, Whitehead MA, Robinson D, O’Neill D, Langhorne P. Comprehensive geriatric assessment for older adults admitted to hospital: meta-analysis of randomised controlled trials. BMJ. 2011; 343:d6553. [PubMed: 22034146]

5. Madden KA, Rockwood K. The health of geriatrics in Canada-more than meets the eye. Can Geriatr J. 2012 Forthcoming. 